ORIGINAL RESEARCH ARTICLE

\title{
The Effectiveness of a Collector Bag for Measurement of Post- partum Hemorrhage
}

\author{
Zahra Abbaspoor ${ }^{1 *}$ and Leila Vaziri ${ }^{2}$
}

$\mathrm{PhD}$ in Reproductive Health, Assistant Professor, Department of Midwifery, Reproductive Health Promotion Research Center, Ahvaz Jundishapur University of Medical Sciences, Ahvaz, Iran ${ }^{1}$; MSc in Midwifery, Department of Midwifery, Faculty of Nursing and Midwifery, Ahvaz Jundishapur University of Medical Sciences, Ahvaz, Iran ${ }^{2}$

*For Correspondence: Email: Abbaspoor_z762@yahoo.com; Phone: +98 6113738331,009166152841

\begin{abstract}
The aim of the study was to assess sensitivity, specificity, positive predictive value (PPV), negative predictive value (NPV) of collector bag and its correlation with hemoglobin $(\mathrm{Hb})$ and hematocrit $(\mathrm{Ht})$ variations. This study, carried on 100 women referred for admission to labor ward of Shohada hospital in Orumeyeh City, Iran, from April to November, 2007. Serum Hb and Ht were measured after admission; a collecting bag placed under the pelvis just after birth and was weighted after delivery. $\mathrm{Hb}$ and $\mathrm{Ht}$ were again assessed at $8 \mathrm{hr}$ after delivery. PPH was defined as blood loss $>500 \mathrm{ml}$ following vaginal delivery. Each $500 \mathrm{ml}$ blood loss accounts for approximately a $3 \%$ change in the $\mathrm{Ht}$ level or a falling in $\mathrm{Hb}$ of $1 \mathrm{~g} / \mathrm{dl}$. With this cut off our noted Sensitivity $=80 \%$, Specificity $=95.7 \%, \mathrm{PPV}=88.9 \%$ and $\mathrm{NPV}=91.8 \%$. The collector bag is a rapid and precise instrument to diagnose of postpartum hemorrhage in the delivery room. It also enables a visual, quantitative and objective estimation of blood loss. (Afr J Reprod Health 2017; 21[1]: 99-103).
\end{abstract}

Key words: Collector bag, Estimating, Laboratory Test, Postpartum Hemorrhage

\section{Résumé}

Le but de l'étude était d'évaluer la sensibilité, la spécificité, la valeur prédictive positive (VPP), la valeur prédictive négative (VPN) du sac collecteur et sa corrélation avec les variations de l'hémoglobine (Hb) et de l'hématocrite (Ht). Cette étude a porté sur 100 femmes envoyées aux spécialistes au service de travail de l'hôpital Shohada dans la ville d'Orumeyeh, en Iran, d'avril à novembre 2007. Les taux de $\mathrm{Hb}$ et $\mathrm{Ht}$ sériques ont été mesurés après l'admission; Un sac de collecte placé sous le bassin juste après la naissance a été pondéré après l'accouchement. Hb et $\mathrm{Ht}$ ont de nouveau été évalués 8 heures après l'accouchement. La $\mathrm{PPH}$ a été définie comme une perte de sang $>500 \mathrm{ml}$ après l'accouchement vaginal. Chaque perte de sang de $500 \mathrm{ml}$ représente approximativement une variation de $3 \%$ du niveau $\mathrm{Ht}$ ou une baisse de $\mathrm{Hb}$ de $1 \mathrm{~g} / \mathrm{dl}$. Avec ceci comme point minimum, nous avons noté la Sensitivité $=80 \%$, Spécificité $=95.7 \%$, VPP $=88,9 \%$ et VPN $=91,8 \%$. Le sac collecteur est un instrument rapide et précis pour diagnostiquer une hémorragie post-partum dans la salle d'accouchement. Il permet également une estimation visuelle, quantitative et objective de la perte de sang. (Afr J Reprod Health 2017; 21 [1]:99-103).

Mots clés: Sac collecteur, estimation, analyse de laboratoire, hémorragie postpartum

\section{Introduction}

Postpartum hemorrhage ( $\mathrm{PPH})$ is one the major causes of maternal mortality and morbidity globally ${ }^{1-4}$. In developed countries, sever PPH occurs in about one percent of deliveries ${ }^{5,6}$ and based on WHO report, about $25 \%$ of maternal mortalities are associated to sever $\mathrm{PPH}^{7}$. In Iran based on the Health Ministry Report in 2006, maternal mortality rate (MMR) was $25 \%$ and $\mathrm{PPH}$ was the main cause of maternal mortality ${ }^{8}$.
Predicting and diagnosing severe PPH remains challenging and most deaths due to sever PPH involve delay in the diagnosis and management of hemorrhage ${ }^{9,10}$. Underestimation of blood loss at delivery time is one the reasons of the delayed diagnosis of blood loss. Many studies indicate that assessment of post-partum blood loss following a vaginal delivery is difficult and visual estimation of blood loss is frequently inaccurate ${ }^{11-13}$. Another method for measuring postpartum blood loss is calculated of $\mathrm{Ht}$ and $\mathrm{Hb}$ variations before and after 
delivery, but these variations take time about 8-12 hr after delivery ${ }^{14}$. Therefore, diagnosis of postpartum blood loss by using $\mathrm{Hb}$ and $\mathrm{Ht}$ is a retrospective method and, also it is not a clinical procedure. Based on this assumption if blood loss objectively measured rather than visually or by $\mathrm{Hb}$ and $\mathrm{Ht}$ variation, before a massive hemorrhage, with an early diagnosis and appropriate management, the incidence of severe $\mathrm{PPH}$ will reduce.

Tourne et $\mathrm{al}^{15}$ showed that a collecting plastic bag, put under the pelvis of the mother just after delivery is a quantitative and objective method of measuring postpartum blood loss. In Tourne's study postpartum hemorrhage was defined by a fall of $\mathrm{Ht}$ more than 10 points (delta $\mathrm{Ht}$ ), or by a fall of $\mathrm{Hb}>3 \mathrm{~g} / \mathrm{dl}$ (delta $\mathrm{Hb}$ ) that were assessed at three days after delivery.

The aim of this study was to assess the sensitivity, specificity, PPV and NPV of collector bag with a postpartum hemorrhage definition $>500 \mathrm{ml}$ blood loss, or a fall of $\mathrm{Ht}>3 \%$ or by a fall of $\mathrm{Hb}>1 \mathrm{~g} / \mathrm{dl}$, was assessed at $8 \mathrm{hr}$ after delivery. The correlation between bag's volume and $\mathrm{Hb}$ and Ht variation was also examined.

\section{Methods}

This was an analytic-diagnostic study that was carried out on 100 women with unique pregnancy at term that undergoing a vaginal delivery in the Labor Ward of Shohada Hospital in Orumeyeh City, Iran. The hospital records more than 200 vaginal deliveries annually. Breech presentations and women with a previous postpartum hemorrhage were excluded.

Serum $\mathrm{Hb}$ and $\mathrm{Ht}$ were measured after admission for labor and were again assessed at 8 hours after delivery. Postpartum hemorrhage was defined by a blood loss $>500 \mathrm{ml}$ or a fall of $\mathrm{Ht}>3 \%$, or a fall of $\mathrm{Hb}>1 \mathrm{~g} / \mathrm{dl}$.

A plastic bag (in size $84^{\times} 28 \mathrm{~cm}$ and thickness of 70 microns) was placed under the mother as soon as the baby was born and before delivery of the placenta and was weighted after delivery.

Data were collected using a checklist filled out for each vaginal delivery, and included information on the woman's age, induction of labor, mode of delivery, number of babies and their birth weight, and outcome data. For deliveries with severe PPH, data regarding the PPH management of obstetric were recorded.
We assessed the sensitivity and specificity of collecting bag using the following thresholds: blood loss $>500 \mathrm{ml}$ or a fall of $\mathrm{Ht}>3 \%$, or a fall of $\mathrm{Hb}>1 \mathrm{~g} / \mathrm{dl}$ (standard definitions) at each of the following time, after admission and 8 hour postpartum. Finally, we calculated the positive and negative predictive values of each volume lost in collecting bag method, assuming PPH prevalence to assess the clinical utility of each measure.

Statistical analyses were performed using SPSS version 13 and Chi square and t-tests were used. The significance level was set at $\mathrm{p}<0.05$.

Written informed consent was obtained from each woman before the study. Each woman was assigned an ID code, ensuring data set anonymity. Women could withdraw from the study at any point. The study design was approved by the institutional Ethics Committee of Ahvaz Jundishapur University of Medical Sciences.

\section{Results}

The results showed collector bag accuracy in assessing postpartum hemorrhage in comparison to $\mathrm{Hb}$ and $\mathrm{Ht}$ variation. In the third stage of labor $73 \%$ of mothers had a $\mathrm{PPH}<500 \mathrm{ml}$ at 2 hours after delivery and $27 \%$ of mothers had a PPH $\geq 500 \mathrm{ml}$ (table 1). The mean volume of blood loss was $299 \pm$

Table 1: Frequency of Blood Loss Volume after Delivery to 2 Hours Later

\begin{tabular}{ll}
\hline Blood loss volume (ml) & Number (\%) \\
\hline$<500$ & $73(73 \%)$ \\
$500-999$ & $21(21 \%)$ \\
$1000-1499$ & $4(4 \%)$ \\
$\geq 1500$ & $2(2 \%)$ \\
Total & $100(100 \%)$ \\
Mean(SD) & $299( \pm 210)$ \\
Min & 57 \\
Max & 1713 \\
\hline
\end{tabular}

$210 \mathrm{ml}(57-1714) \mathrm{ml}$. Also the results showed that $70 \%$ of women had a fall in $\mathrm{Ht}<3 \% 8$ hours after delivery by comparing to before delivery. Thus, based on the PPH definition they had a normal blood loss, and only $30 \%$ of cases had a fall in $\mathrm{Ht}$ $\geq 3 \%$. The mean fall in $\mathrm{Ht}$ was $2.9 \pm 2.8(0-13)$ percent (table 3 ). Also, $71 \%$ of women had a fall in $\mathrm{Hb}<1 \mathrm{~g} / \mathrm{dl}$, and only $29 \%$ of mothers had a fall in $\mathrm{Hb} \geq 1 \mathrm{~g} / \mathrm{dl}$. The mean fall in $\mathrm{Hb}$ was $0.9 \pm 0.8 \mathrm{~g} / \mathrm{dl}$ (0-4.5) (table 3). Based on table 2 the sensitivity of collecting bag for $\mathrm{Hb}$ was $79.3 \%$, for $\mathrm{Ht}$ was $80 \%$ and for $\mathrm{Hb}-\mathrm{Ht}$ was $82 \%$. The specificity of the test for $\mathrm{Hb}$ was $94.4 \%$; of $\mathrm{Ht}$ was $95.7 \%$ and for $\mathrm{Hb}-\mathrm{Ht}$ 


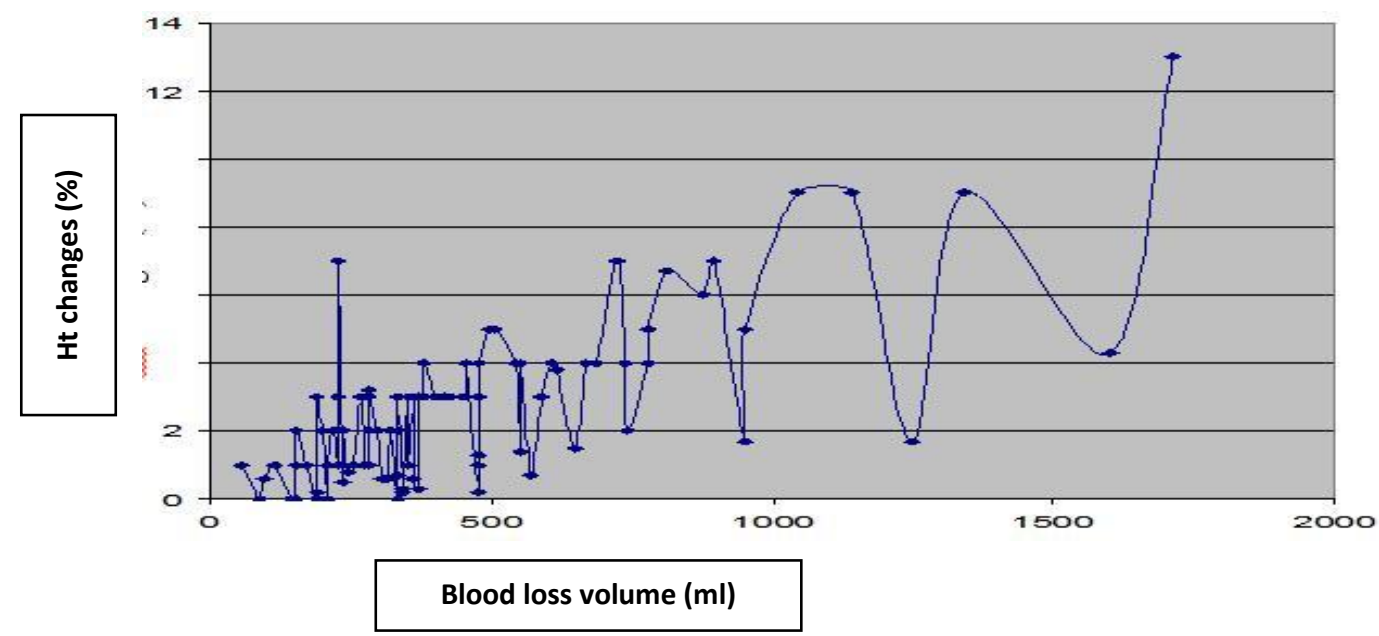

Figure 1: The Relation between blood loss volume and Ht changes

The plot is linear and shows the proportional of the collection bag volume with drop in hematocrit after hemorrhage. This chart also shows that there is a direct relation between changes in pre and postpartum hematocrit and blood loss volume collected in bag.

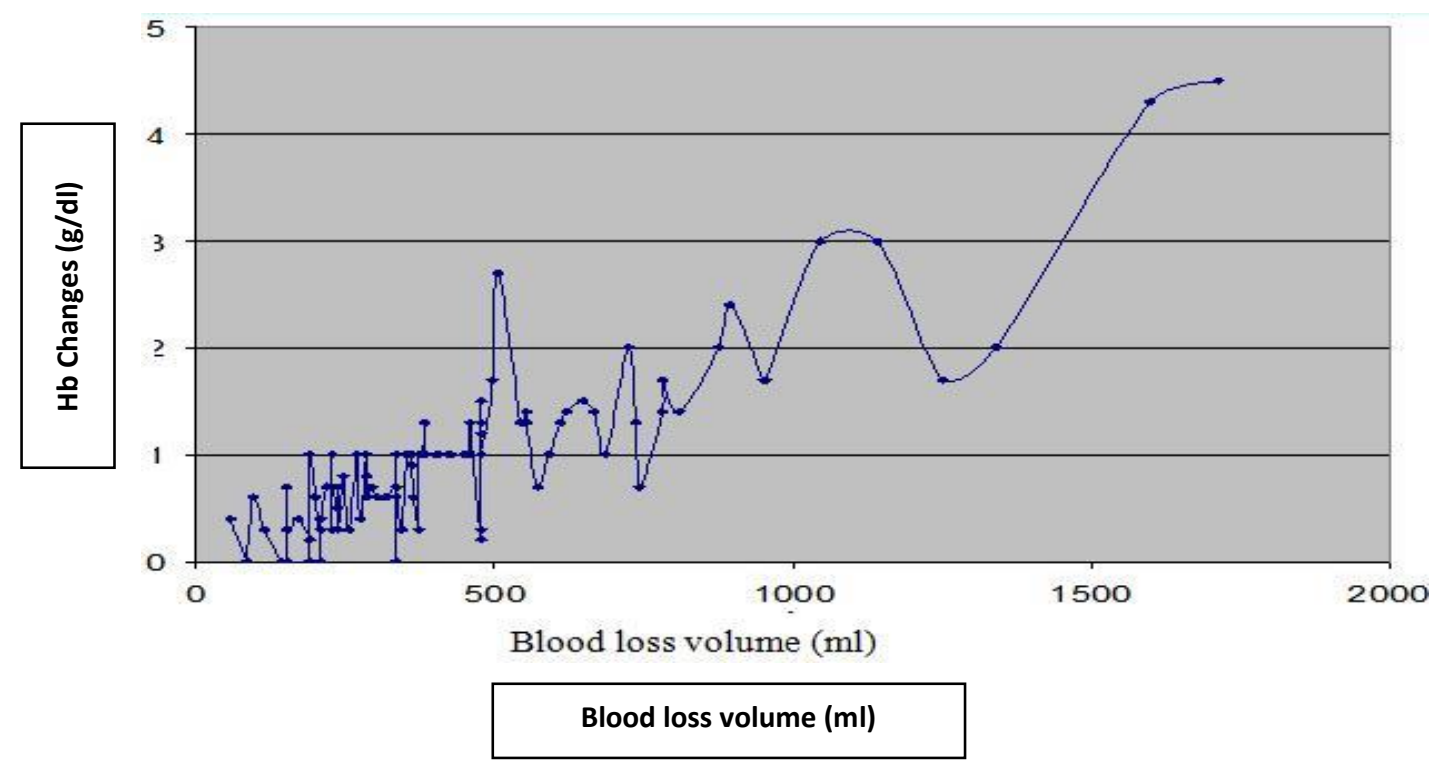

Figure 2: The Relation between blood loss volume and $\mathrm{Hb}$ changes

The plot is linear and shows the proportional of the collection bag volume with drop in hemoglobin after hemorrhage. This chart also shows that there is a direct relation between changes in pre and postpartum hemoglobin and blood loss volume collected in bag.

was $95.7 \%$. Also PPV of collector bag for $\mathrm{Hb}$ was $85.2 \%$, for $\mathrm{Ht}$ was $88.9 \%$ and for $\mathrm{Hb}-\mathrm{Ht}$ was $100 \%$ and NPV of collecting bag for $\mathrm{Hb}$ was $91.8 \%$, for $\mathrm{Ht}$ was $91.8 \%$ and for $\mathrm{Hb}-\mathrm{Ht}$ was $98.5 \%$.

\section{Discussion}

The collector bag had a high sensitivity, specificity, positive predictive value and negative predictive value in the diagnosis of postpartum hemorrhage. At the time this study was conducted, there was only one published study regarding the use of collecting bags in predicting $\mathrm{PPH}^{15}$. In Tourne study the $\mathrm{Hb}-\mathrm{Ht}$ was measured after admission and again three days after delivery and post- partum hemorrhage was defined by a fall of $\mathrm{Ht}$ more than 10 points or by a fall of $\mathrm{Hb}$ more than $3 \mathrm{~g} / \mathrm{dl}$. The results showed the sensitivity of collector bag for $\mathrm{Hb}$ was $38.77 \%$ and for $\mathrm{Ht}$ was $34.21 \%$, that was lower than the sensitivity in our study.

It was probably due to blood loss during three days after delivery that although was low, but it could lead to PPH. In specificity, PPV and NPV in 
Table 2: Sensitivity, Specificity, PPV and NPV of Blood Loss Measurement by Collector Bag Compared to Reference Standard of $\mathrm{Hb}-\mathrm{Ht}$

\begin{tabular}{lllccc}
\hline $\begin{array}{c}\text { Collector bag } \\
\text { Validity (\%) }\end{array}$ & Sensitivity & Specificity & $\begin{array}{r}\text { Positive } \\
\text { Predictive } \\
\text { Value }\end{array}$ & $\begin{array}{r}\text { Negative } \\
\text { Predictive } \\
\text { Value }\end{array}$ & Precise \\
\hline Hemoglobin & $79.3 \%$ & $94.4 \%$ & $85.2 \%$ & $91.8 \%$ & $90 \%$ \\
Hematocrit & $80 \%$ & $95.7 \%$ & $88.9 \%$ & $91.8 \%$ & $91 \%$ \\
Hb -Ht & $82.1 \%$ & $95.7 \%$ & $100 \%$ & $98.5 \%$ & $89 \%$ \\
\hline
\end{tabular}

Table 3: $\quad$ Frequency of True Positive, False Positive, True Negative and False Negative of Collector Bag for Hemoglobin and Hematocrit

\begin{tabular}{lllll}
\hline $\begin{array}{l}\text { Collector Bag } \\
(\mathbf{m l})\end{array}$ & \multicolumn{2}{l}{ Hematocrit (\%) } & \multicolumn{2}{l}{ Hemoglobin $(\mathrm{g} / \mathbf{d l})$} \\
\cline { 2 - 5 } & $<3$ & $\geq 3$ & $<1$ & $\geq 1$ \\
& $(\mathrm{n}=70)$ & $(\mathrm{n}=30)$ & $(\mathrm{n}=71)$ & $(\mathrm{n}=29)$ \\
\hline$<\mathbf{5 0 0}(\mathbf{n}=\mathbf{7 3})$ & 67 & 6 & 67 & 6 \\
$>\mathbf{5 0 0}(\mathrm{n}=\mathbf{2 7})$ & 3 & 27 & 4 & 23 \\
\hline
\end{tabular}

the two studies were comparable. Zhang et $a l^{16}$ studied the effectiveness of using a transparent plastic collector bag for measurement of postpartum blood loss in 25381 women in 13 European countries. Results showed that the incidence of severe PPH was $1.71 \%$ in the intervention group (Collecting bag) compared to $2.06 \%$ in the control group. The difference was not statistically significant and it concluded that the use of a collector bag after vaginal delivery did not reduce the rate of severe PPH as compared to visual estimation of postpartum blood loss ${ }^{16}$.

However, prior studies have had mixed results in comparing the accuracy of measured blood loss to quantify methods of blood loss. Patel and colleagues ${ }^{17}$ found a positive correlation between measured blood loss and other laboratory methods of measuring blood loss by photo spectrometry. Their study was limited by a relatively small sample size $(n=10)$. Other studies have reported promising correlations between measured blood loss and laboratory methods that quantify the blood loss using absorbent paper or sanitary pads and photometric measurement of alkaline hematin ${ }^{18}$.

\section{Conclusion}

Future studies are needed to test the effectiveness of collector bag in randomize trials in developing countries. Based on this study results the collector pelvic bag is a rapid and precise procedure and it also enables a visual, quantitative, and objective estimation of blood loss and because of the simplicity of collector bag to diagnose of postpartum hemorrhage and its very low cost, it is suggested that the collector pelvic bag be used widely as a routine preventive measure in delivery rooms. Midwives should be educated on the use of collector bags.

\section{Acknowledgments}

The study was supported by a grant from Vice Chancellor of research, Ahvaz Jundishapur University of Medical Sciences. The authors are indebted to those who commented on early drafts of this article, in particular, they are indebted to Mohamad Hossin Haghighizadeh, MSc in statistics, Department of Statistics and Mathematics, for his full and helpful comments and doing statistical analysis and they also appreciate Dr Jalal Emam, $\mathrm{PhD}$ in laboratory Sciences, Department of Laboratory Sciences, Faculty of Paramedical for doing the laboratory testing and his helpful comments.

\section{Declaration of Authorship}

This study was Master's thesis by LV, who participated in acquisition, analysis, and interpretation of data and drafting of the manuscript. ZA was the supervisor of the thesis and participated in the conception and design of the study, data analysis and interpretation, drafting and revision of the manuscript.

\section{Competing Interests}

All authors declare: no support from any organization for the submitted work; no financial relationships with any organizations that might have an interest in the submitted work in the previous 3 years; no other relationships or activities that could appear to have influenced the submitted work.

\section{References}

1. Roberts C, Ford J, Algert C, Bell J, Simpson J, Morris J. Trends in adverse maternal outcomes during childbirth: a population-based study of severe maternal morbidity. BMC pregnancy and childbirth 2009; 9(1): 7. 


\section{Abbaspoor \& Vaziri}

2. Khan KS, Wojdyla D, Say L, Gülmezoglu AM, Van Look PFA. WHO analysis of causes of maternal death: a systematic review. The Lancet 2006; 367(9516): 1066-74.

3. Callaghan WM, MacKay AP, Berg CJ. Identification of severe maternal morbidity during delivery hospitalizations, United States, 1991-2003. American journal of obstetrics and gynecology 2008; 199(2): 133. e1-. e8.

4. Cunningham FG, Bloom SL, Leveno KJ. Williams Obstetrics 22 Ed; 2005.

5. Zhang W, Alexander S, Bouvier-Colle M, Macfarlane A. MOMS-B Group. Incidence of severe pre-eclampsia, postpartum haemorrhage and sepsis as a surrogate marker for severe maternal morbidity in a European population-based study: the MOMS-B survey. BJOG 2005; 112(1): 89-96.

6. Al-Zirqi I, Vangen S, Forsen L, Stray-Pedersen B. Prevalence and risk factors of severe obstetric haemorrhage. BJOG: An International Journal of Obstetrics \& Gynaecology 2008; 115(10): 1265-72.

7. AbouZahr C. Antepartum and postpartum haemorrhage. Global Burden of Disease and Injury Series 1998; 3: 165-90.

8. Iran Ministry of Health and Medical Education (IMHME), Organization of Mother and Child Health, 2006. Available from: 〈http://www.fhp.hbi/FHPPages/ MothersOf ficeHealthINDpage.htm $\rangle$ (in Persian).

9. Berg CJ, Harper MA, Atkinson SM, Bell EA, Brown HL, Hage ML, et al. Preventability of pregnancy-related deaths: results of a state-wide review. Obstetrics \& Gynecology. 2005;106(6):1228-34.

10. Mander R, Smith GD. Saving Mothers' Lives (formerly Why Mothers die): reviewing maternal deaths to make motherhood safer 2003-2005. Midwifery 2008;

\section{Collector Bag and Post-Partum Hemorrhage}

24(1): 8-12

11. Duthie SJ, Ven D, Yung GLK, Guang DZ, Chan SYW, Ma HK. Discrepancy between laboratory determination and visual estimation of blood loss during normal delivery. European Journal of Obstetrics \& Gynecology and Reproductive Biology 1991; 38(2): 119-24.

12. Stafford I, Dildy GA, Clark SL, Belfort MA. Visually estimated and calculated blood loss in vaginal and cesarean delivery. American journal of obstetrics and gynecology 2008; 199(5): 519. e1-. e7.

13. Dildy III GA, Paine AR, George NC, Velasco C. Estimating blood loss: can teaching significantly improve visual estimation? Obstetrics \& Gynecology 2004; 104(3): 601.

14. Combs CA, Murphy EL, Laros Jr RK. Factors associated with hemorrhage in cesarean deliveries. Obstetrics \& Gynecology 1991; 77(1): 77.

15. Tourne G, Collet F, Lasnier P, Seffert P. Usefulness of a collecting bag for the diagnosis of post-partum hemorrhage. Journal de gynécologie, obstétrique et biologie de la reproduction 2004; 33(3): 229.

16. Zhang WH, Deneux-Tharaux C, Brocklehurst P, Juszczak E, Joslin M, Alexander S. Effect of a collector bag for measurement of postpartum blood loss after vaginal delivery: cluster randomised trial in 13 European countries. BMJ: British Medical Journal 2010; 340.

17. Patel A, Goudar SS, Geller SE, Kodkany BS, Edlavitch SA, Wagh $\mathrm{K}$ et al. Drape estimation vs. visual assessment for estimating postpartum hemorrhage. Int J Gynaecol Obstet 2006; 93: 220-224.

18. Chua S, Ho LM, Vanaja K, Nordstrom L, Roy AC, Arulkumaran S. Validation of a laboratory method of measuring postpartum blood loss. Gynecol Obstet Invest 1998; 46: 31-33. goi46031 [pii]. 